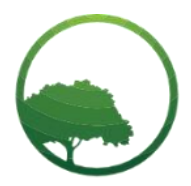

Research in Business \& Social Science

IJRBS VOL 10 NO 4 ISSN: 2147-4478

\title{
Blockchain technology as a panacea for procurement corruption in digital era
}

\author{
G. Ogunlela Oyebanjo ${ }^{(a) *(1)}$ H. Ojugbele Olabode ${ }^{(b)}$ (D) K. Tengeh Robertson ${ }^{(b)}$ \\ ${ }^{(a, b)} \mathrm{Dr}(s)$, Research Fellow(s), Department of Public Administration \& Governance, Cape Peninsula University of Technology, Corner of Hanover \\ and Tennant Street, Room E3.57, 3rd Floor, Engineering Building, District Six Campus, Cape Town. South Africa \\ (c) Professor, Head of Department, Public Administration \& Governance, Cape Peninsula University of Technology, Corner of Hanover and \\ Tennant Street, Room E3.57, 3rd Floor, Engineering Building, District Six Campus, Cape Town. South Africa
}

\author{
ARTICLE INFO \\ Article history: \\ Received 18 May 2021 \\ Received in rev. form 04 June 2021 \\ Accepted 06 June 2021 \\ Keywords: \\ Public Procurement, Corruption, \\ Digitization, Blockchain, South Africa \\ JEL Classification \\ D73
}

\begin{abstract}
A B S T R A C T
Corruption in public institutions is a significant problem that stifles economic, social and environmental development worldwide. This predominates when there is a lack of transparency, inadequate record-keeping, and low public accountability. Accordingly, the questions this paper intends to provide answers to are two-fold. Firstly, what are the recurring patterns of procurement corruption in the South Africa (SA) public sector? Secondly, how can digital technology deployment assist in checking this trend? Desktop method was adopted through literature examination of studies relating to corruption, procurement, blockchain and digitization. We conclude by proposing a model/framework for adopting and using blockchain technology in public institutions to minimise corruption and the time taken for contract document preparation and acceptance. This study contributed to knowledge by evaluating the issues associated with public procurement and how blockchain and digitization can be adopted to help stern the tide of corruption in public institutions.
\end{abstract}

() 2021 by the authors. Licensee SSBFNET, Istanbul, Turkey. This article is an open access article distributed under the terms and conditions of the Creative Commons Attribution (CC BY) license (http://creativecommons.org/licenses/by/4.0/).

\section{Introduction}

Public procurement is an essential governance tool that plays a crucial role in development. It is employed by both the state, developmental and funding agencies to drive their development agendas (Ambe, 2016). In addition, public procurement is used by governments globally to increase public sector productivity "through savings and economies of scale" (OECD, 2016: 3). In the South African context it is the major mechanism for facilitating service delivery (Kimeu, 2014) and redressing the country's historical socioeconomic imbalance, which accumulated from the discriminatory practices of the old apartheid regime (Munzhedzi, 2016).

However, this laudable economic tool is often tainted with corruption (Lindskog et al., 2010) to which it is highly prone because of the volume of financial resources that is involved, as well as its multi-stakeholders nature and the traditional opacity in terms of information flow and decision making surround procurement (Munzhedzi, 2016; Williams-Elegbe, 2018). The impact of corruption in the public sphere is colossal and when not properly managed, it undermines the development of a nation and also impacts negatively on the quality of life of the citizen (Williams-Elegbe, 2018) by exacerbating poverty, deprivation and exclusion since in most cases corrupt practices in public institutions always boil down to mismanagement of monies meant for the provision of basic and essential services to the populace (Kimeu, 2014).

Contrary to common assumption, the malady of public sector corruption is a worldwide one. As a result, concerted efforts have always been undertaken to determine the best course of action. OECD (2016b) recommends several approaches, one of which is the adoption of e-procurement, or more precisely, the digitisation of the procurement process.

* Corresponding author. ORCID ID: 0000-0001-5982-116X

(C) 2021 by the authors. Hosting by SSBFNET. Peer review under responsibility of Center for Strategic Studies in Business and Finance. https://doi.org/10.20525/ijrbs.v10i4.1222 
Digitisation of public procurement is gaining momentum globally; this drive has been ascribed to how procurement is being handled by various public institutions, thus leading to corrupt practices, where funds set aside for development initiatives end up in the pockets of public officers. According to Srai and Lorentz (2019:15), digitisation of procurement has to do with the "use of advanced digital techniques for procurement purposes". Batran et al. (2017) argued that advanced technologies, such as big data analytics, cloud computing, and the Internet of Things (IoT), can bring about the necessary transformation required from possible collaboration among supply chains globally.

Therefore, it is construed that digitization of procurement practices becomes very important when the desired reduction in cost and efficiency is essential (Kosmol, Reimann \& Kanfuan, 2019). Although blockchain is mostly used in the financial sector (Zheng et al. 2017), these authors further argued that blockchain-use is unfolding in different sectors of the economy worldwide. As such, they posit that institutions can begin to make use of blockchain as a process improvement mechanism. For example, Hileman and Rauchs (2017) believed that the primary focus of blockchain centres on money related matters since the first blockchain was implemented as a currency-related application.

The architecture of blockchain is founded on the principle of a decentralised database, thus making data storage possible in different nodes, making it accessible from various locations simultaneously. This assertion is corroborated by Nicoleti (2017), who posited that a centralised database would enable all stakeholders in the procurement process to interact seamlessly, therefore making the process more reliable, with little disruption.

Decentralisation of the purchasing order (PO), according to Harer (2018), makes it possible for new stakeholders involved in supplies to be onboarded easily into the blockchain, based on the available information at their disposal, since the system is protected with no fear of data insecurity. The questions this paper intends to provide answers to are two-fold. Firstly, what are the recurring patterns of procurement corruption in the SA public sector? Secondly, how can digital technology deployment assist in checking this trend?

The assumption, globally, is that procurement is supposed to bring about efficiency to improve service delivery (Kosyan \& Mil'kina, 2019). However, contrary to this belief, is that the procurement process in South Africa deviates from this assumption due to it being marred with inefficiency, lack of transparency and corrupt practices (The Republic of South Africa, National Treasury, 2015). Therefore, poor quality procurement practices in South Africa call for a deep understanding of the challenges and possible ways of overcoming these through improved procurement initiatives; this is important for both practical and policy implications. We concluded by developing a proposed model that will enable the adoption of blockchain in public institutions to help reduce corruption and the time required for processing and approval of contract documents. The remaining part of this paper is structured as follows, immediately following this introduction is the conceptualisation of public procurement, then a discussion on South Africa public procurement, procurement corruption in South Africa, followed by the theoretical perspective and its relationship to procurement, next is the overview of blockchain technology and role of digitization in improving public governance, an explanation of blockchain and its importance to procurement and its solution to public sector corruption, then proposition based on developed framework, followed by the limitations and lastly conclusion and implications.

\section{Conceptualising Public Procurement}

Generically, procurement refers to the process through which goods and services are acquired from a third party under a contracting arrangement. Ababio et al. (2008) noted that the underpinning goal is to achieve the best feasible cost in a manner that meets the timing, locational, quality and quantity goals of the buyer. When extrapolated to the public sector, public procurement will then refer to the process by which the government or public institutions purchases goods and services directly to meet the ultimate need required to help in performing its core functions of service delivery (Ambe, 2016; Mafunisa \& Nsingo, 2014) or pursuing of public welfare (Williams \& Quinot, 2007). Sewpersadh and Mubangizi (2017) noted that public institutions or enterprises in this context refer to establishments that are governed by public law. And in most cases, if not all, the seller is usually the private sector (Mantzaris, 2014).

Public procurement is a big part of the economy of any country and a major driver of economic growth (Lindskog et al., 2010). It is usually a process involving the sequence of activities that start with the assessment of needs, followed by the award of contracts, contract management processes, and finally payment (OECD, 2016b).

\section{South African Public Procurement}

Pre 1995, public procurement in South Africa is characterised by the patronage of a minority group and established business, excluding the vast majority of the population and small businesses (Williams, 2007). Post-apartheid democratic government in South Africa following the global trend chose to use procurement as one of the tools of democratising development. Various relevant papers (green and white) and pieces of legislations gradually emerged with the sole aim of promoting inclusive government contracting without compromising the concept of value for money, promoting responsible corporate citizenship, and blocking avenue for leakages and corruption (Williams, 2007). The South African constitution clearly defines the primary goal of procurement. Section 217(1) advocates for the establishment of a procurement system that is fair, equitable, transparent, competitive and cost-effective. It goes on further in section 217(2) to clarify that the system envisaged above does not contradict the provision of a procurement policy that may provide for (1) categories of preference in the allocation of contracts and (2) the protection or advancement of persons, or 
categories of persons, disadvantaged by unfair discrimination. A snapshot of the relevant legislations geared towards ensuring the desired national procurement system is provided in Table 1 below.

Table 1: Some of the Primary Legislations that Regulate Public Procurement

\begin{tabular}{ll}
\hline Act & Meaning in respect of procurement \\
\hline $\begin{array}{l}\text { Public Finance Management Act } 1 \text { of } \\
1999\end{array}$ & $\begin{array}{l}\text { Establishes a regulatory framework for SCM, which includes procurement in national and provincial } \\
\text { departments and state-owned enterprises. }\end{array}$ \\
\hline Promotion of Administrative Justice & $\begin{array}{l}\text { Establishes fair administrative procedures, permits those affected by unfair administrative action to } \\
\text { request reasons for such administrative action, and requires administrators to respond to such requests } \\
\text { (Administrative actions are presumed to have been taken without good cause where an administrator } \\
\text { fails to respond within the prescribed period). In addition, it provides for procedures for the judicial } \\
\text { review of administrative actions and remedies in proceedings for judicial review, including the } \\
\text { prohibition of an administrator from acting in a particular manner, setting aside the administrative action, } \\
\text { correcting the defective action and ordering the administrator to pay compensation. }\end{array}$ \\
\hline
\end{tabular}

The Promotion of Establishes how preferential procurement policies are to be implemented

Equality and the

Prevention of Unfair

Discrimination Act 4 of 2000

Preferential Procurement Policy Establishes how preferential procurement policies are to be implemented

Framework Act 5 of 2000

Construction Industry Development Establishes how the Board can promote and implement policies, programmes and projects, including Board Act 38 of 2000 those aimed at procurement reform, standardization and uniformity in procurement documentation, practices and procedures within the framework of the procurement policy of the government, through the establishment of: (1) a national register of contractors (and if required, consultants and suppliers) to manage public sector procurement risk and facilitate public procurement; (2) a register of projects above a particular financial value, with data relating to contracts awarded and completed, and a best practice project assessment scheme; (3) best practices which establish a code of conduct for the parties engaged in construction procurement.

Broad-based Black Economic Empowerment Act 53 of 2003 Establishes a code of good practice to inform:

- The development of qualification criteria for the issuing of licences or concessions, the sale of state-owned enterprises and for entering into partnerships with the private sector; and

- The development and implementation of a preferential procurement policy.

Local government: Municipal Finance Establishes a regulatory framework for supply chain management which includes procurement in Management Act 56 of 2003 municipalities and municipal entities.

Prevention and

Combating of Corrupt

Activities, Act 12 of 2004 Makes corruption and related activities an offence; establishes a Register in order to place certain restrictions on persons and enterprises convicted of corrupt activities relating to tenders and contracts; Source: Ambe (2016: 281) and places a duty on certain persons holding a position of authority to report corrupt transactions.

It is worth stressing that section 217 of the constitution emphasises that all public procurement should take place in a fair, equitable, transparent, competitive, and cost-effective manner. Unfortunately, however, the reality is that public procurement in the Republic is being subjected to a gruesome onslaught of what is fast approaching a state of systemic corruption.

\section{Conceptualising procurement corruption in South Africa}

Public procurement is particularly susceptible to corruption because of the magnitude of financial resource involved, among other things. The role of human ethical deficit too cannot be downplayed (Kimeu, 2014). "Corruption erodes trust, weakens democracy, hampers economic development and further exacerbates inequality, poverty, social division and the environmental crisis" (Transparency International, 2020). Corruption is a global phenomenon identified as a major obstacle to procurement innovation in the public sector. Such innovations are expected to optimise public service delivery by introducing new processes and/or technology (Bolton, 2016). Transparency International (2009) captures corruption as the abuse of power for private gain. A descriptive definition by Thornhill (2012: 140) stated that corruption "is offering or granting, directly or indirectly to a public official or any other person, of any goods of monetary value, or other benefits, such as a gift, favour, promise or advantage for himself or herself or any other person or entity, in exchange for any acts or omission in the performance of his/her public functions" Thus, it can be said that corruption, simply put, refers to any deviation from the established procedure, processes or legislative provision for any form of personal, political or other benefits or motives during the performance of public function (Munzhedzi, 2016; Thornhill, 2012).

Annually, the South Africa government spend close to R800 billion on procurement. However, it is construed that about half of this amount may be embezzled by corrupt officers involved in the procurement process (Williams-Elegbe, 25, October, 2019). Despite the various guiding legislations, especially the Prevention and Combating of Corrupt Activities Act, 2004 (Act 12 of 2004 ), 
procurement corruption remains rife in South Africa. The Prevention and Combating of Corrupt Activities Act prescribe punishment and sanctions for corrupt practices and place certain obligations on public servants to report corrupt practices. The punishment includes prison terms and recommendation to place particulars of unscrupulous persons or enterprises in a defaulters' register which bars them from participating in government procurement for several years not greater than 10 years.

Nevertheless, this has not yielded any fruitful result, because corrupt procurement forms part of the allegations identified in the provinces and submitted to the public protection office, procurement related corruption is estimated to be approximately $50 \%$ of all the complaints. According to Martin-Ortega and O'Brien (2019), in their study, iterate that a report by the South Africa auditorgeneral's office shows that of recent, there has been an increase in fraudulent activities related to procurement activities, these instances indicate that these measures put in place to help stem the activities of corrupt practices has not fully achieved its objectives. South African public procurement, according to the South African treasury (2015), is characterised by many issues ranging from:

i. Non-understanding of the strategic importance of Public procurement (PP) because most people involved seem to not have a proper understanding of the socio-economic influence of purchasing decisions taken by them during the course of their work.

ii. Structural problems affecting the system, with most decision makers lacking the requisite skills needed to effectively carry out their jobs.

iii. Lack of proper definition of roles and responsibilities causing conflict between regular officials and political office holders, which has been linked as one of the causes of corrupt practices in PP.

Further, public procurement corruption occurs in South Africa due to multi-party collusion, which often includes vendors and public servants or a coalition of vendors. Matlala and Dintwe (2013) stated this could be either of the following formats:

i. Employee-vendor collusion: Bid rigging in favour of vendor in return for gratification to the employee(s)

ii. Vendor fraud: overpricing or substitution of inferior good often with the aid of receiving employees in exchange for gratification or compensation

iii. Vendors collusion: essentially collusion among vendors resulting in price fixing

Munzhedzi (2016) mentioned several specific and deliberate corrupt acts which include price inflation, award of contracts to friends or family, not advertising tenders, improper constitution of bid committees or failure by members to declare conflict of interest. Listing what could be regarded as more clandestine practices, Mantzaris (2014: 68) mentioned "bribery, extortion, embezzlement, nepotism, patronage systems, fraud, kickback schemes, false invoices, overpaying, fronting in Black Economic Empowerment (BEE) companies, inflated prices, unnecessary purchases, payments made for goods or services not received, ghost suppliers on the 'preferred suppliers list', the use of shell companies, and 'facilitation fees' required by state officials (a type of bribery)".

\section{Theoretical perspective and its relationship to Procurement}

Blockchain technology was originally designed to time stamp documents so they cannot be tampered with, having initially been designed for approving legal documents so these cannot be interfered with once formally accepted and signed. Subsequently, the potential was realised when it was used to create Bitcoin (cryptocurrency) for financial institutions to move money around and pay for transactions. Gradually, it has now become an avenue whereby transactions are simplified through decentralisation, differentiating its application from the traditional procurement process model. For example; in the payment system, the application takes place in three stages; Bitcoin is sent using a private key, payment is verified using a public key and lastly, money is received, thus removing the involvement of many institutions totally from the process chain.

Therefore, blockchain theory can be assumed to be a new way of working, through streamlined, existing processes using technology and automation, thus making processes more dynamic. The theory of Supply chain practice view (SCVP) can be applied to help provide insight into procurement digitization. It is a holistic framework that can assist in gaining an understanding of how supply chain partners adopt inter-organisational digital procurement practices and the performance achieved, when used SCPV is capable of providing a helicopter view and supply chain-specific overview required for an in-depth view of procurement digitization (Cartel et al. 2017b).

The main motive of SCPV application in operations management is its capability to assist organisations to initiate inter-organisation supply chain practices, for the purpose of performance improvement. The SCPV latches onto the Bromiley and Ran (2016) practicebased view, a theoretical foundation for strategic management research, and extends it to the inter-organisation level of analysis. SCPV is argued to be adequate as a theoretical background for procurement digitization because of its capability to provide a helicopter view by making use of the antecedents to and application of digitization in procurement and performance (Cartel et al. 2017b).

\section{Overview of Blockchain technology and Role of Digitization in improving public governance}

Initially, blockchain was used as a cryptocurrency initiative, however, this concept recently changed and it is now extended to the application of smart contracts in public procurement. This technology helps to make information available to the public online and they can interrogate the process, since this allows government to makes information available in a more transparent way. According 
to Rauches et al. (2018), blockchain is a technology that entails distributed ledgers, premised in ensuring that the exchange of decentralized information and data is stored in a secured way to enable accountability, transparency and efficiency, making updates take place independently, seamlessly and enabling replication to take place in real-time to all nodes within the system.

Furthermore, blockchain has the capability to support shared record keeping, independent validation, tamper proofing and many stakeholders can reach an agreement on matters of interest in a transparent way, therefore promoting transparency, efficiency and improved sustainability of process (Accenture, 2017). Data stored in a decentralised manner onto many nodes makes it possible for updates to occur independently in all nodes, with these characteristics promoting transparency and data security, as there is data visibility in all nodes. This makes processes transparent and since they can be replicated in real-time across nodes, it is difficult to manipulate data, thus preventing unauthorised change, editing or deletion across all nodes at the same time, which help to secure data (Fast \& Coppi, 2019).

The availability of numerous nodes tends to provide or increase transparency and helps to further secure data storage within the database (Nelson, 2018), therefore promoting accountability as well as trust within the system. Unlike the problem encountered in the traditional centralised system, where risk associated with data manipulation is high, the blockchain system serves as a lever to help overcome this challenge. This is achieved by employing decentralized data storage in blocks, where new transactions are only added to the past transaction chain and deletion or modification of information previously stored within the chain is not allowed.

According to Ray (2018), one of the strengths of blockchain is its ability to record events, perform record management, facilitate transaction processing, asset tracking and a possibility of voting. In their view, Rauches et al. (2018) iterated that distributed ledger systems (DTLs) should be able to meet the following minimum criteria:

i. A set of authoritative records (the ledger) is shared across multiple parties/ nodes, thus leading to shared record-keeping.

ii. All parties agree on this set of shared records through multi-party consensus, either in a permissioned or permission-less system.

iii. Parties can independently verify the transaction records on the ledger (Independent validation)

iv. Parties can detect any unilateral or non-consensus changes to transactions (Tamper evidence)

v. Individual parties cannot easily or unilaterally change the transaction history of the ledger (Tamper resistance).

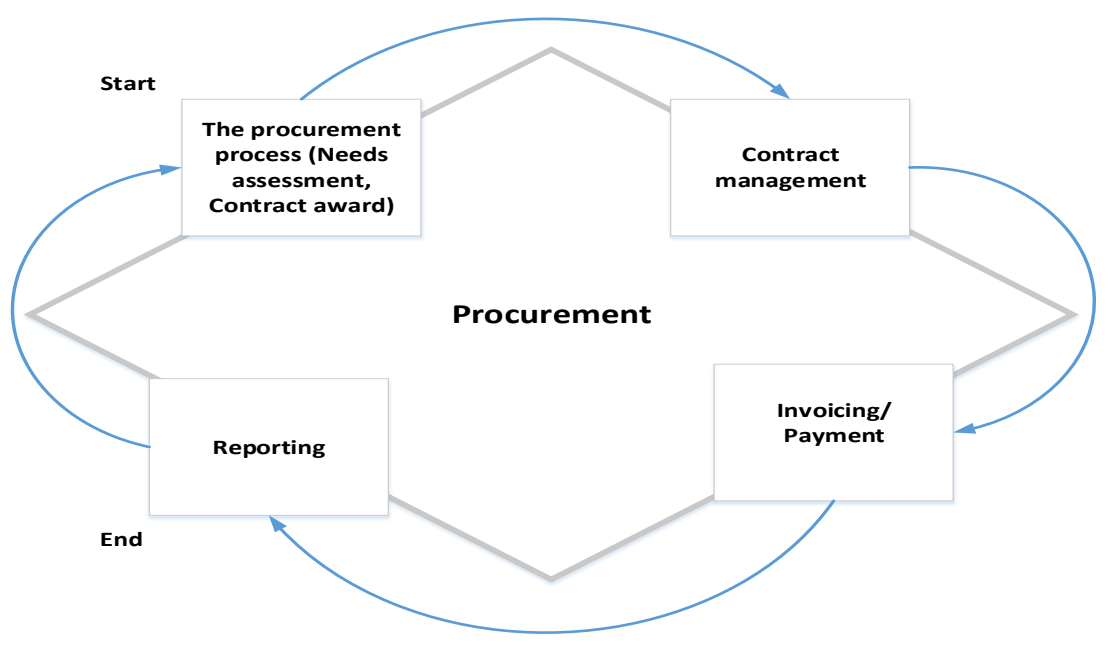

Figure 1: Traditional method of public procurement; Source: Developed by authors 2021

The main motive of the blockchain application is to help provide solutions to traditional problems within a system, such as the public procurement process. All the illustrated traditional procurement processes (figure 1) can be streamlined through technology and automation adoption, for example blockchain, to ensure transparency, efficiency and trust within the system. At the same time, updates can also be achieved in real-time and across all locations. One such way of achieving these is through implementing a smart contract, which entails contracts that act automatically according to computer coding, to update the blockchain ledger, most especially a call-off contract.

In contract management automation, we can quickly verify suppliers, ensuring up-to-date records, enhanced information-sharing and the principle of transparency, sharing of best practice, keeping a register of all contracts, and real-time data management for suppliers and security. In addition, product tracking is ensured (auto order of products to set levels) once the system is updated when new blocks are added, and when there is overstock in one particular location, you can send to another location in need before re-stocking; this will reduce time to order and deliver. 


\section{Explaining Blockchain}

Blockchain is a technology used as a distributed ledger that rides on a point-to-point network, enabling trust between unknown parties within the system and enabling seamless payment without human intervention (Nakamoto, 31 October, 2008). It serves as a medium for keeping the history, thereby making it difficult for anyone to alter the values once verified through mutual agreement by the various network peers involved in the transaction. Security of data and the transaction is achieved through cryptography, thus enabling secure transaction, integrity and privacy (Baranwal, 2020) further, this technology provides a platform for data storage, arrangement and contract code execution, referred to as smart contract. This is achieved through an agreement that contracts are carried out in line with the allocated code, mutually agreed by all participating nodes in the network (Baranwal, 2020).

\section{Importance of blockchain in procurement}

Unlike traditional systems of managing funds and contracts, blockchain can make fund management and the contracting process more transparent and secure and ensure accountability and efficiency of process, in a way not possible through the conventional system (Kumar, 2017). Thus, the main stakeholders can verify transactions within the system to confirm its validity and legitimacy, even when third party maintaining account balances are notarised. Furthermore, because of its decentralized nature (Perera, Nanayakkara \& Weerasuriya, 2021), this makes services available to stakeholders in a reliable, fast, secure and transparent manner.

In conventional public institutions, management of government funds and budget approvals used to be a nightmare, making it a timewasting venture to obtain the necessary approvals from the various government departments. However, these challenges can be surmounted with implementing a blockchain system, where funds can be allocated almost immediately upon approval by the relevant authorisation levels. More so, issues associated with fund mismanagement will be prevented, since all transactions are stored in a non-erasable format, allowing public institutions to trace allocation of funds and spending patterns (Perera et al., 2021). Additionally, deletion or data manipulation is prevented, because when this is initiated, approvals must be obtained from the various levels before such a process can be allocated, thus making it difficult for any single person to perpetrate fraud within the system. At the same time, all transactions can be completed online from transaction initiation to closure, therefore reducing waiting time for approvals.

A more important aspect of blockchain is the smart contract feature, which comprises computer enabled transaction protocols, making it possible for automatic execution of pre-prepared contracts once all contract conditions are met (Marabito, 2017). Consequently, it is possible to by-pass any intermediary stakeholder or a single point of approval for a contract to be signed.

\section{Components of Blockchain}

The various components that make up blockchain architecture are:

Digital asset: In order to prevent invalidation of data within the system, blockchain makes it possible for documents to be signed digitally using its document notarization capability, which ensures digital transaction integrity, through recording of a fingerprint, for example, the hash file checksum onto the blockchain (Xu, et.al. 2017)

Digital signature: Everyone involved in the blockchain process makes use of a digital signature allocated with both private and public keys attached to their wallet, which can be used to sign transactions (Private key) prior to its distribution on the network. This process of digital signature entails two major components, namely the process of signing and the verification, therefore, when a user wants to sign a transaction, a private key is issued for data encryption, while the public key is used for verification and sender data integrity.

Multi-signature protocol: This is the process whereby stakeholders are able to sign using their private keys for transactions with protocols agreed to by not just many people, but also where an account is jointly owned, as well as in an organisation where multiple levels of approval are required for a transaction; all stakeholders are required to sign with their private keys before such transactions can be processed.

Smart Contract: This is an add-on to blockchain that enables automation of complicated transactions. Thus, the process is usually initiated once set criteria are met.

\section{Benefits of Blockchain}

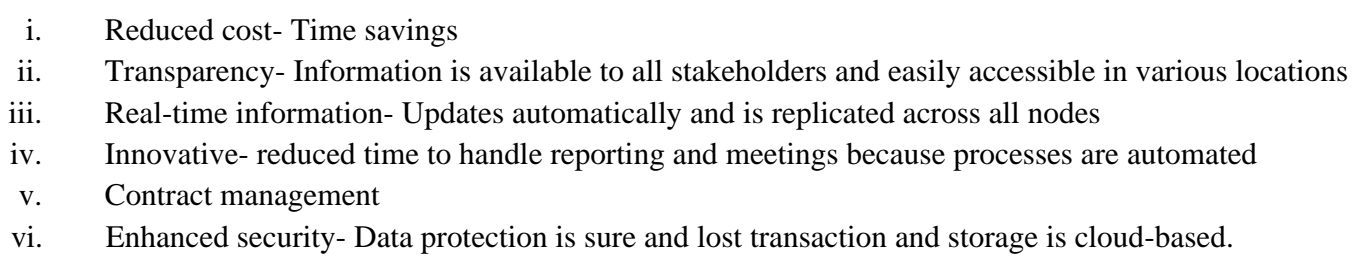

\section{Challenges of blockchain adoption}
i. Ideological changes (Embracement of change by the public sector)
ii. GDPR legislation and sharing of information- most people will only see their account
iii. Ability to adopt new technology- training, installation and use 
iv. Availability of techology

v. Investment in change (Money and people)- money is involved and it takes a considerable level of time before people can adapt

vi. Risk of decentralization and supplier engagement/ compliance and loss of control

\section{Blockchain solution to public sector corruption/ Application of Blockchain to help stem corrupt practices}

Globally, corruption thrives mostly in government procurement, with the assumption that roughly $\$ 9.5$ trillion is earmarked by governments for public procurement (Raycraft \& Lannquist, 2020), whilst these funds are set aside for construction of infrastructure, healthcare and other developmental initiatives. It was further iterated that some of these funds will end up in the pockets of certain public servants, involved directly or indirectly in the procurement process. According to the United Nations (UN) and Organisation for economic cooperation and development (OECD), this could amount to 10 to $30 \%$ of funds allocated for procurement.

Although, in an effort to stamp out procurement corruption, governments have instituted policies and procedures in the past, which proved to be inadequate to help achieve the set objectives (Raycraft \& Lannquist, 2020). Nevertheless, this drive can now be achieved through blockchain-based procurement, through its capability to help ensure processes are tamper-evident, increase transparency, as well as the use of 'smart contract'. Furthermore, this capability makes it difficult for any official to unilaterally remove bid records and procurement comments from the system once bid or tenders are submitted.

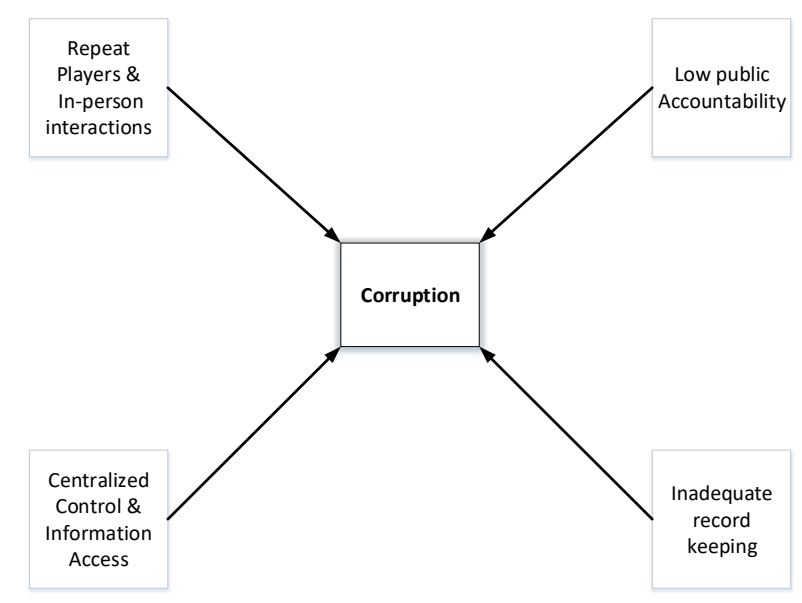

Figure 2: Framework for possible causes of corruption in public procurement; Source: Adapted from Raycraft \& Lannguist (2020) and modified by the authors, 2021

Iterated below are the ways Blockchain capacity can assist to help mitigate the traditional procurement problem:

i. Centralized control and information access: Due to decentralization of information ownership and authority (Impartial) the tendency of any one person to manipulate transactions due to their level of authority is reduced, thus making it impossible for data to be manipulated.

ii. Low Public Accountability: Real-time transparency and accountability (Transparent), the possibility of manipulating data construed to be the norm in the traditional process will be reduced or eliminated in the blockchain system as transactions take place in real-time and everyone in the nodes will be notified and able to verify the transaction, therefore making it less likely to be tampered with.

iii. Repeat players and In-person interactions: Traceable transactions and automated functionalities (Transactional) mean any transaction that takes place within the blockchain is automated and updated immediately across all the nodes in the network, which can be traced to the initiator.

iv. Inadequate record keeping: Tamper-evident record (Immutable) on, for instance, the conventional system where data or records can be manipulated by either one or a group of persons. This is not possible in the blockchain system because transactions are tamer-proof, since all concerned persons must approve manipulation of any record before this can be carried out.

The problem of corruption in government procurement can be reduced with the implementation of a blockchain system, with a framework that can be applied to the various processes illustrated below. 


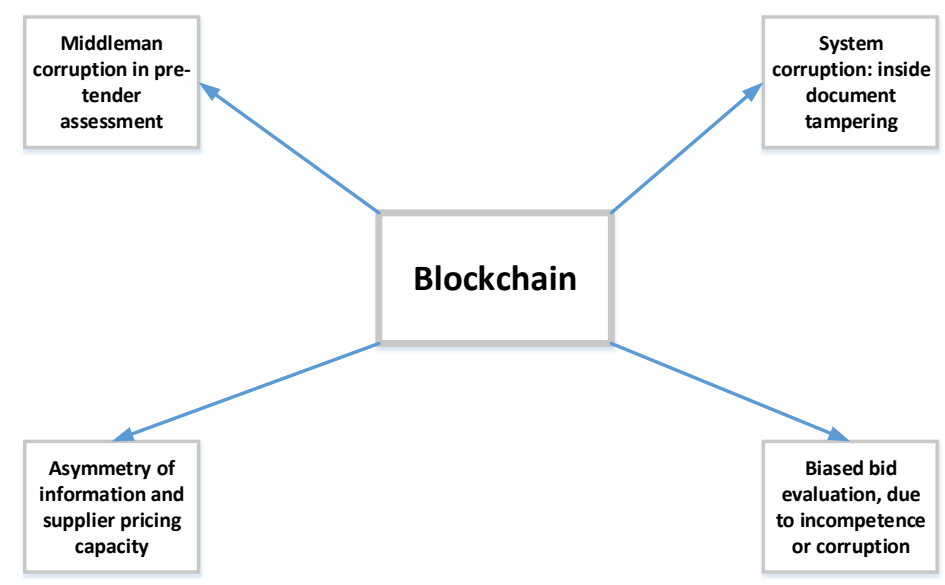

Figure 3: Proposed framework for mitigating procurement corruption in the public institutions

\section{Proposition}

Proposition I: Digitization/ Blockchain has significant impact on pre-tender assessment by isolating middlemen.

Proposition II: Digitization/ Blockchain has significant impact on system corruption and inside document tampering.

Proposition III: Digitization / Blockchain has significant impact on information asymmetry/ irregularities and supplier pricing

Proposition IV: Digitization/ Blockchain has significant impact on bid evaluation.

These propositions can be tested through the adoption of either Qualitative or Quantitative research methodology or combination of both (Mixed Method) by selecting some public officials, suppliers and procurement stakeholders in some government institutions in South Africa who are involved in the procurement process. According to the World Bank, challenges being experienced by African countries in the implementation and adoption of digital procurement can be attributed to the following three factors (Anthony, 2018) namely, lack of necessary physical infrastructures, inadequate information technology infrastructure and the use of archaic administrative procedures. Blockchain is a technology-based solution with the characteristics to help ensure transactions are transparent and secure, as well as introducing new ways of dealing with new services (Kumar, 2017). It was additionally iterated that delays experienced annually when various government departments allocate budgets will be eliminated with the use of the blockchain system, with allocation of such funds done with little if any effort and almost instantaneously. Furthermore, most loopholes that can be explored to perpetrate fraud will be reduced or eliminated and due to its ability to ensure transparency, blockchain enables citizens can start holding public officials accountable for their actions (Kumar, 2017). In most cases, government data are stored in silos, making most transactions vulnerable to manipulation by individuals. This situation can be appropriately addressed through the implementation of blockchain, since it is developed as an encoded digital ledger, made available on numerous computers either on publicly- or privately-owned networks, making it difficult for modification of any of the blocks by a single individual, as modifications will have to be verified and approved by all stakeholders (Kumar, 2017). The implementation of Smart contract in the blockchain system can be used to address all the above issues being experienced in the traditional method of public procurement. Smart contract has the capability to assist stakeholders involved in the procurement contract to digitally effect contracts thereby eliminating intermediaries within the procurement system, with blockchain assisting to enhance information transparency. South Africa public procurement is fragmented, where each entity operates in silos (Williams-Elegbe, 2018), its operations is backed by many legislations which gives clear direction on how procurement process is carried out. Also the office of Chief Procurement Officer (OCPO) is charged with the responsibility to provide oversight role on procurement practices in the country. The OCPO role is complex and fragmented, thus posing numerous challenged limiting the effectiveness of the process. These challenges however, can be reduced or eliminated with the implementation of blockchain and smart contract. Blockchain can help prevent all the above anomalies, especially where there is an emergency and the need to award contracts quickly, without giving due consideration to competitive bidding and ensuring due process is observed. A typical example is the procurement of PPE during the COVID-19 pandemic, when contracts need to be put in place. Although corrupt practices vary from one country to the other, it is argued by Raycraft and Lannguist (2020) that the causes are common in nature, for example; "inadequate record keeping, low public accountability, repeat and close interaction between private sector and government officials and centrally controlled processes". All these leave procurement process susceptible to corrupt practices and inefficiency. In South Africa, COVID-19 procurement was done in a hurry, thus making it possible for officials to bypass procedure, which facilitated corruption to be perpetrated; however, this could have been averted through the use of a blockchain-based procurement system.

\section{Conclusions}

The role of blockchain in procurement practices is gaining momentum globally, to help streamline processes for transparency. As such, digitization of procurement practices becomes very important when the desired reduction in cost, as well as efficiency in their 
processes becomes crucial. Our findings have implications for academics, procurement managers and policy makers. First, our proposed framework could help procurement managers and policy makers to gain further insight into how procurement practices can be improved in public institutions. Secondly, we contend that, this framework will enable policy makers to further conceptualise how better blockchain can be utilised to enhance procurement processes so as to reduce corruption to the lowest possible level and thus contributing to the theoretical, conceptual and policy perceptions relating to public procurement digitization. Further, this study help to institute further discussions on the role of blockchain through digitization could pay in helping to stimulate reduction in corruption and increased transparency in the public procurement digitization literature.

Public procurement is supposed to bring about efficiency in a manner that will improve service delivery globally. Contrary to this belief, is that the procurement process in South Africa totally deviates from this assumption, due to it being marred with inefficiency, lack of transparency and corrupt practices. Digitisation of public procurement is gaining momentum globally; this drive has been ascribed to the manner in which procurement is being handled by various public institutions leading to corrupt practices. This study contributed to knowledge by evaluating the issues associated with public procurement and how blockchain and digitization can be adopted to help stern the tide of corruption in public institutions. Our arguments were founded on the theory of Supply chain practice view (SCVP) by latching onto the Bromiley and Ran (2016) practice-based view, a theoretical foundation for strategic management research, and extends it to the inter-organisation level of analysis. We have been able to demonstrate in this study and studies carried out by several authors the importance of procurement as an essential governance tool that plays a crucial role in development by governments globally to increase public sector productivity "through savings and economies of scale" and how this laudable economic tool is often tainted with corruption. Advanced technologies are being proposed globally to help streamline processes for transparency, as such, digitization of procurement practices becomes very important when the desired reduction in cost, as well as efficiency in their processes becomes crucial. This study is limited because it is purely a literature analysis of related topics in procurement, Blockchain technology and digitization in public institutions and therefor no data was collected through field observations. It is advised that the proposition in this study be tested through empirical data to further substantiate our findings in the literature. Further it only covered literature relating to public procurement corruption and digitization using blockchain technology.

\section{References}

Ababio, E., Vyas-Doorgapersad, S., \& Mzini, L. (2008). Service delivery and under-expenditure: strategies towards effective control of public funds. Journal of Public Administration, 43(si-1), 3-15.

Accenture Labs (201)7. Blockchain for good: 4 guidelines for transforming social innovation organisations (www.accenture.com/ t20180102T200432Z_w__/us-en/_acnmedia/ PDF-68/Accenture-808045 BlockchainPOV-RGB. pdf\#zoom=50)

Ambe, I. M. (2016). Public procurement trends and developments in South Africa. Research Journal of Business and Management, $3(4), 277-290$.

Anthony, A. (2018). The use of e-procurement in the South Africa procurement law: Challenges and prospects, Law, Democracy \& development: 22(1), 39-47.

Baranwal, P.R. 2(020). Blockchain Based Full Privacy Preserving Public Procurement, Research and Development, Talentica Software (India) Pvt Ltd, Pune. Pp. 1-15. https:// 10.1007/978-3-030-59638-5_1

Batran, A., Erben, A., Schulz, R., and Sperl, F., (2017). Procurement 4.0: A survival guide in a digital, disruptive world. Campus, Frankfurt.

Bolton, P. (2016). Public procurement as a tool to drive innovation in South Africa. Potchefstroom Electronic Law Journal/Potchefstroomse Elektroniese Regsblad, 19(1).

Bromiley, P., and Rau, D., (2016). Operations management and the resource based view: Another view. J. Oper. Manag. 41, $95-106$.

Carter, C.R., Kosmol, T., and Kaufmann, L., (2017b). Toward a supply chain practice view. J. Supply Chain Manag. 53 (1), $114-$ 122.

European Conference on Information Systems: Beyond Digitization - Facets of Socio-Technical Change, ECIS (2018), AIS Electronic Library, Portsmouth, pp. 1-17.

Fast, L., and Coppi, G. (2019), Feb. Blockchain and Distributed Ledger Technologies in the Humanitarian Sector. Overseas Development Institute: https://www.odi.org/publications/11284-blockchain-and-distributed-ledger-technologieshumanitarian-sector.

Hardwick, F.S., Akram, R.N., and Markantonakis, K. (2016). Fair and Transparent Blockchain based Tendering Framework - A Step towards Open Governance, ISG-SCC, Royal Holloway, University of London, Egham, United Kingdom.

Härer, F. (2018). Decentralized business process modeling and instance tracking secured by a blockchain, in Bednar, P.M, Frank, U. and Kautz, K. (Eds), 26th

International, T. (2009). Global Corruption Barometer I. Secretariat.

International, T. (2020). What is corruption. International Secretariat. Retrieved 28th May from https://www.transparency.org/en/what-is-corruption

Kimeu, S. (2014). Corruption as a challenge to global ethics: the role of Transparency International. Journal of Global Ethics, 10(2), 231-237.

Kosyan N.G., and Mil'kina I.V. (2019). Blockchain in the public procurement system (2019) E Management, 2 (1), pp. $33-41$. https://10.26425/2658-3445-2019-1-33-41. 
Kumar, S. (2017). Blockchain: The solution to public sector corruption. November 2nd, 2017, Published in Articles: EE Publishers, Articles: PositionIT. https://www.ee.co.za/article/blockchain-solution-public-sector-corruption.html

Lindskog, H., Brege, S., \& Brehmer, P.-O. (2010). Corruption in public procurement and private sector purchasing. Journal of Organisational Transformation \& Social Change, 7(2), 167-188.

Mafunisa, K., \& Nsingo, J. (Eds.). (2014). Safeguarding ethics and accountability in the public sector (2nd ed.). Jutan.

Mantzaris, E. (2014). Public procurement, tendering and corruption: Realities, challenges and tangible solutions.

Matlala, M., \& Dintwe, S. (2013). Procurement fraud red flags in theSsouth African municipalities' corporate governance. Conference Proceedings published by the South African Association of Public Administration and Management (SAAPAM),

Morabito, V. (2017). Business Innovation Through Blockchain, Springer International Publishing, Cham.

Munzhedzi, P. H. (2016). South African public sector procurement and corruption: Inseparable twins? Journal of Transport and Supply Chain Management, 10(1), 1-8.

Nakamoto, S., 31 October 2008. Bitcoin: A Peer-to-Peer Electronic Cash System. Tech. rep. pp. 1-11. Available: https://www.bitcoin.org/bitcoin.pdf.

Nelson, P. (2018). Primer on blockchain: how to assess the relevance of distributed ledger technology to international development (www.usaid.gov/ sites/default/files/documents/15396/USAID-Primer- Blockchain.pdf)

Nicoletti, B. (2017). The Future: Procurement 4.0, inAgile Procurement, PalgraveMacmillan, Champp. 189-230.

Organisation for Economic Co-operation and Development, O. (2016)a. Public procurement for sustainable and inclusive growth: Enabling reform through evidence and peer reviews https://www.oecd.org/gov/ethics/Public-Procurementfor\%20Sustainable-and-Inclusive-Growth_Brochure.pdf

Organisation for Economic Co-operation and Development, O. (2016b). Preventing Corruption in Public Procurement. OECD. https://www.oecd.org/gov/ethics/Corruption-Public-Procurement-Brochure.pdf

Perera, S., Nanayakkara, S., Weerasuriya, T. (2021). Blockchain: The Next Stage of Digital

Procurement in Construction. Academia Letters, proof. Pp. (1-10).

Rauchs, M. and Hileman, G. (2017). 2017 Global blockchain benchmarking study, Working paper [3040224], Cambridge Centre for Alternative Finance, University of Cambridge, 21 September.

Rauchs, M., Glidden, A., Gordon, B., Pieters, G., Recanatini, M., Rostand, F., Vagneur, K. and Zhang, B. (2018). Distributed ledger technology systems: a conceptual framework. Cambridge: Cambridge Centre for Alternative Finance, University of Cambridge (https://papers.ssrn.com/sol3/papers.cfm?abstract_id=3230013)

Raycraft, R.D and Lannguist, A. (2020). How governments can leverage policy and blockchain technology to stunt public corruptionReport https://www.weforum.org/agenda/2020/06/governments-leverage-blockchain-public-procurement-corruption/

Sewpersadh, P., \& Mubangizi, J. C. (2017). Using the law to combat public procurement corruption in South Africa: Lessons from Hong Kong. Potchefstroom Electronic Law Journal/Potchefstroomse Elektroniese Regsblad, 20(1).

Srai, J.S., and Lorentz, H., (2019). Developing design principles for the digitalisation of purchasingand supply management. J. Purch. Supply Manag. 25 (1), 78-98.

The Republic of South Africa National Treasury. (2015). Public Sector Supply Chain Management Review, Pretoria, 0002 Private Bag X115, Pretoria, 000140 Church Square, Pretoria, 0002 Private Bag X115, Pretoria, 0001.

Thornhill, C. (2012). Improving local government transformation in South Africa. Administratio Publica, 20(3), 128-143.

Williams-Elegbe, S. 25, October, (2019). Public procurement, corruption and blockchain technology in South Africa: A preliminary legal inquiry: available at: https:ssrn.com/abstract $=3458877$.

Williams, S. (2007). The use of exclusions for corruption in developing country procurement: The case of South Africa. Journal of African Law, 1-38.

Williams, S., \& Quinot, G. 2007. Public procurement and corruption: the South African response. South African Law Journal, 124(2), 339-363.

Xu, X., Weber, I., Zhu, L., Staples, M., Bosch, J., Bass, L., Pautasso, C., and Rimba, P. (2017). A Taxonomy of Blockchain-Based Systems for Architecture Design, in 2017 IEEE International Conference on Software Architecture (ICSA), 2017, pp. 243252.

Zheng, Z., Xie, S., Dai, H., Chen, X. and Wang, H. (2017). An overview of blockchain technology: Architecture, consensus, and future trends, in Karypis, G. and Zhang, J. (Eds), 2017 IEEE.

Publisher's Note: SSBFNET stays neutral with regard to jurisdictional claims in published maps and institutional affiliations.

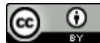

(C) 2021 by the authors. Licensee SSBFNET, Istanbul, Turkey. This article is an open access article distributed under the terms and conditions of the Creative Commons Attribution (CC BY) license (http://creativecommons.org/licenses/by/4.0/).

International Journal of Research in Business and Social Science (2147-4478) by SSBFNET is licensed under a Creative Commons Attribution 4.0 International License. 